\title{
PENGARUH BRAND ASSOCIATION DAN BRAND AWARENESS TERHADAP BRAND LOYALTY MELALUI BRAND TRUST PADA START UP FINTECH OVO
}

\author{
Rio Era Deka ${ }^{1}$, Nurhajati ${ }^{2}$, Nuzulul Rachma ${ }^{3}$ \\ ${ }^{1}$ Mahasiswa Magister Manajemen Pascasarjana Universitas Islam Malang \\ Email : riodyka@gmail.com \\ ${ }^{2}$ Magister Manajemen Pascasarjana Universitas Islam Malang \\ Email : nurhajati@unisma.ac.id \\ ${ }^{3}$ Magister Manajemen Pascasarjana Universitas Islam Malang \\ Email : lus_rachma@yahoo.com
}

\begin{abstract}
Abstrak
Tujuan penelitian ini adalah Mengetahui pengaruh tidak langsung Brand Association dan Brand Awareness terhadap Brand Loyalty Melalui Brand Trust pada start up OVO. Jenis penelian ini adalah explanatory research dengan menggunakan pendekatan kuantitatif. Populasi dalam penelitian ini adalah pengguna OVO pada mahasiswa Universitas Islam Malang di Kota Malang, Jawa Timur. Teknik pengambilan sampel dilakukan dengan purposive sampling dan didapatkan sampel sebanyak 120 responden. Hasil penelitian menunjukan bahwa Pengaruh tidak langsung antara variabel brand Awareness terhadap brand loyalty melalui variabel brand trust diperoleh dari hasil pengaruh langsung antara variabel brand awareness terhadap brand trust dan pengaruh langsung antara variabel brand trust terhadap variabel brand loyalty sehingga pengaruh tidak langsung. Hal ini dapat diartikan bahwa ada pengaruh tidak langsung variabel brand association dan brand awareness terhadap brand loyalty melalui brand trust, serta semakin tinggi brand trust maka brand loyalty akan semakin meningkat.
\end{abstract}

Kata kunci : Brand Association, Brand Awareness, Brand Trust, Brand Loyalty

\begin{abstract}
The purpose of this study was to find out the indirect influence of Brand Association and Brand Awareness on Brand Loyalty Through Brand Trust at the start up of OVO. This type of research is explanatory research using a quantitative approach. The population in this study were OVO users in Malang Islamic University students in Malang City, East Java. The sampling technique was done by purposive sampling and obtained a sample of 120 respondents. The results showed that the indirect effect of brand awareness on brand loyalty through brand trust variables was obtained from the direct effect of brand awareness variables on brand trust and the direct effect of brand trust variables on variable brand loyalty so that indirect effects. This can be interpreted that there is an indirect effect of brand association and brand awareness of brand loyalty through brand trust, and the higher brand trust, brand loyalty will increase.
\end{abstract}

Keyword : Brand Association, Brand Awareness, Brand Trust, Brand Loyalty

\section{PENDAHULUAN}

Pemanfaatan internet berkembang lebih cepat daripada dugaan sebelumnya. Salah satunya pemanfaatan yang berkembang cepat adalah hadirnya pembayaran non-tunai. Pembayaran non-tunai sebelumnya menjadi pilihan dengan sistem kartu yang diterapkan baik oleh perbankan ataupun penjual (seperti kartu member kedai yang dapat di-top-up). Namun penetrasinya sangat sedikit, terbukti salah satunya dalam melakukan 
pembayaran misalnya, pemanfaatan kartu kredit masih minim. Mobile payment menghadirkan cara baru. Ketergantungan masyarakat dengan ponsel dan fiturnya menjadi kesempatan luar biasa menggarap segmen ini di Indonesia.

Di bawah naungan LippoX sebagai perusahaan digital payment milik grup perusahaan Lippo, sebuah smart financial apps diluncurkan layanan belanja dengan produk pembayaran digital yang bernama OVO, aplikasi ini mencoba mengakomodasi berbagai kebutuhan terkait dengan cashless dan mobile payment. Aplikasi OVO saat ini tersedia untuk platform Android dan iOS. OVO menggunakan sistem poin reward, yang disebut dengan OVO Point, untuk menjaga dan meningkatkan traksi pengguna.

Start up OVO begitu familiar dikalangan masyarakat terutama pada mahasiswa Universitas Islam Malang. Rata-rata mahasiswa sekarang adalah mahasiswa generasi millenial yang melek teknologi. Mereka sering menggunakannya untuk transaksi grab dalam membayar grab bike maupun memesan makanan.

Menurut Lee and Lau(1999) Dalam membangun dan mengembangkan brand trust, perusahaan harus memahami tiga karakteristik penting sebagai determinan kepercayaan pelanggan, yang pada akhirnya akan mengarah pada loyalitas pelanggan. Tiga karakteristik kunci bagi kesuksesan hubungan antara pelanggan dan perusahaan adalah karakteristik merek, karakteristik perusahaan, dan karakteristik hubungan pelanggan-merek. Pada masyarakat umum masih khawatir akan hilang saldonya. Masyarakat masih belum percaya meskipun OVO sudah bekerjasama dengan bank swasta.Tujuan penelitian ini adalah Mengetahui pengaruh tidak langsung Brand Association dan Brand Awareness terhadap Brand Loyalty Melalui Brand Trust pada start up OVO.

\section{KAJIAN TEORI}

Brand Association (Asosiasi Merek) berkenaan dengan segala sesuatu yang berkaitan dengan memory pelanggan terhadap sebuah merek. Karena itu dalam asosiasi merek menurut Temporal (2002:44) "Agar benar-benar bisa menonjol diantara merek-merek lainnya suatu merek harus mempunyai hubungan emosional yang unik". Pada umumnya asosiasi merek yang membentuk brand image menjadi pijakan konsumen dalam keputusan pembelian dan loyalitasnya pada merek tersebut. Dalam prakteknya banyak sekali asosiasi dan variasi dari brand association yang dapat memberikan nilai bagi suatu merek, dipandang bagi sisi perusahaan maupun dari sisi pengguna berbagai fungsi asosiasi.

Asosiasi Merek (Brand Association) adalah sesutau ynag berkaitan dengan ingatan mengenai sebuah produk. Asosiasi ini tidak hanya eksis, namun juga memiliki sutu tingkat kekuatan. Keterikatan suatu merek akan lebih kuat apabila dilndasi pada banyak pengalaman atau penampakan untuk mengkomunikasikannya.

Asosiasi merek adalah segala kesan yang muncul di benak seseorang yang terkait dengan ingatannya mengenai suatu merek. Menurut David A.Aaker (1997) asosiasi merek adalah segala sesuatu yang berkaitan secara langsung maupun tidak langsung dengan ingatan konsumen 
terhadap suatu merek. Berbagai asosiasi merek yang saling berhubungan akan menimbulkan suatu rangkaian yang disebut brand awareness. Semakin banyak asosiasi yang saling berhubungan, semakin kuat brand awareness yang dimiliki oleh merek tersebut (Durianto dkk, 2004).

brand awareness adalah kesanggupan seseorang calon pembeli untuk mengenali atau mengingat kemabli bahwa suatu merek merupakan bagian dari kategori merek tertentu. Menurut East (1997: 29) "Brand ewearness is the recognition and recall of a brand and its differentiation from other brands in the field:" artinya adalah pengakuan dan pengingatan dari sebuah merek dan pembedaan dari merek yang lain yang ada di lapangan. Jadi brand awareness adalah kemampuan seseorang untuk mengingat suatu merek dan menjadikannnya berbeda bila dibandingkan dengan brand atau merek lainya. Ada 4 tingkatan dalam brand awareness yaitu:

a. Unaware of brand (tidak menyadari merek) merupakan tingkat yang paling rendah dalam piramida kesadaran merek. Dimana konsumen tidak menyadari akan adanya suatu merek.

b. Brand recognition (pengenalan merek) tingkat minimal dari kesadaran merek. Hal ini penting pada saat seorang membeli, memilih sesuatu merek pada aat melakukan pembelian.

c. Brand recall (pengingatan kembali terhadap merek) ini didasarkan pada permintaan seseorang untuk menyebutkan merek tertentu dalam suatu kelas produk. Hal ini diistilahkan denganpengingatan kembali tanpa bantuan, karena berbeda dari tugas pengenalan, responden tidak perlu dibantu untuk memunculkan merek tersebut.

d. Top of mind (puncak pikiran) apabila seseorang ditanya langsung tanpa memberi bantuan pengingatan dan orang tersebut dapat menyebutkan satu merek, maka mereka paling banyak disebutkan pertama kali merupakan puncak pikiran. Dengan kata lain, merek tersebut merupakan utama dari berbagai merek yang ada di benak konsumen.

Menurut Tjahyadi (2006: 55) kepercayaan pelanggan pada merek (Brand Trust) didefinisikan sebagai keinginan pelanggan untuk bersandar pada sebuah merek dengan risikorisiko yang dihadapi karena ekspetasi terhadap merek akan menyebabkan hasil yang positif. Kepercayaan cukup penting dalam relational exchange. Menurut Morgan (2004: 83), kepercayaan merupakan cornerstone of the strategic partnership karena karakteristik hubungan melalui kepercayaan sangat bernilai yang mana suatu kelompok berkeinginan untuk menjalankan komitmen terhadap dirinya atas hubungan tersebut. Kepercayaan merupakan harapan dari pihak-pihak dalam sebuah transaksi, dan risiko yang terkait dengan perkiraan dan perilaku terhadap harapan tersebut. Kepercayaan memiliki peran yang penting dalam pemasaran industri. Dinamika lingkungan bisnis yang cepat memaksa pemasaran perusahaan untuk mencari cara yang lebih kreatif dan fleksibel untuk beradaptasi. Menurut Tjiptono (2008: 38) untuk tetap bertahan dalam situasi tersebut, perusahaan akan mencari cara yang kreatif melalui pembentukan hubungan yang kolaboratif dengan 
pelanggan. Kepercayaan dianggap sebagai cara yang paling penting dalam membangun dan memelihara hubungan dengan pelanggan dalam jangka panjang. Komitmen terhadap suatu hubungan didefinisikan sebagai suatu keinginan yang terus-menerus untuk mempertahankan suatu hubungan jangka panjang yang bernilai (Zaltman, 2012: 56).

Dari pemaparan diatas dapat disimpulkan bahwa kepercayaan merek adalah kesediaan konsumen untuk mempercayai suatu merek dengan segala resikonya karena adanya harapan dibenak mereka bahwa merek tersebut akan memberikan hasil yang positif kepada konsumen sehingga akan menimbulkan kesetiaan terhadap suatu merek.

Aaker (1997) mendefinisikan loyalitas merek adalah suatu ukuran keterkaitan seorang pelanggan pada sebuah merek. Konsumen yang memiliki loyalitas kuat terhadap suatu merek akan tetap melanjutkan pembelian produk tersebut, meskipun saat ini banyak bermunculan berbagai merek di pasar yang menawarkan karakteristik produk yang lebih unggul serta dapat memberikan jaminan peningkatan perolehan laba perusahaan di masa mendatang (Durianto, dkk, 2004).

Dalam Astuti dan Cahyadi (2007), pengertian loyalitas adalah sebagai bentuk perilaku pelanggan yang loyal terhadap merek dan tidak berganti merek. Sedangkan menurut Assael (1995) loyalitas merek didasarkan atas perilaku konsisten pelanggan untuk membeli sebuah merek sebagai bentuk proses pembelajaran pelanggan atas kemampuan merek memenuhi kebutuhannya. Selain sebagai bentuk perilaku pembelian yang konsisten, loyalitas merek juga merupakan bentuk sikap positif pelanggan dan komitmen pelanggan terhadap sebuah merek di atas merek lainnya sebagaimana dikemukakan oleh Dharmmesta(1997) dalam Astuti dan Cahyadi (2007) Loyalitas merek dan pengalaman menggunakan sebuah merek tidak terjadi tanpa melalui tindakan pembelian (Astuti dan Cahyadi, 2007). Hal ini membedakan loyalitas merek dengan elemen ekuitas merek lainnya di mana pelanggan memiliki kesadaran merek, persepsi kualitas, dan asosiasi merek tanpa terlebih dahulu membeli dan menggunakan merek.

Dalam penelitian ini dapat dibuat suatu kerangka pemikiran yang dapat menjadi landasan dalam penulisan ini, yang pada akhirnya akan dapat diketahui variabel mana yang paling berpengaruh dominan dalam keputusan pembelian konsumen. Kerangka pemikiran ini dapat digambarkan sebagai berikut :

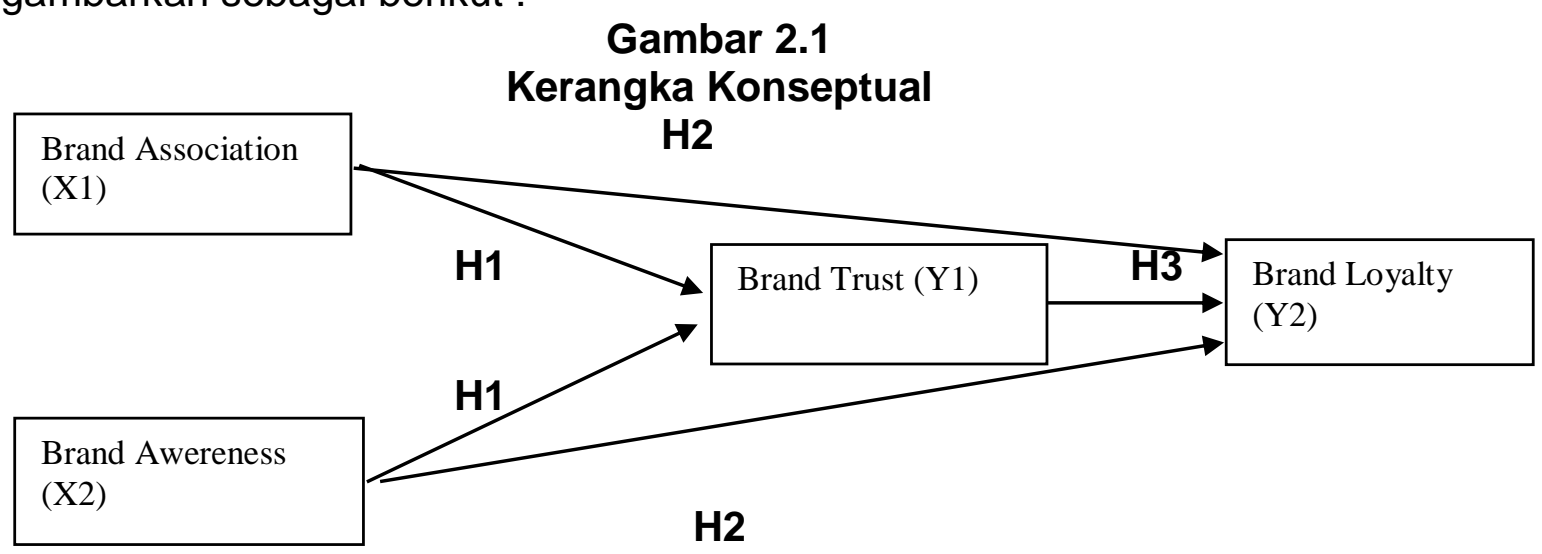


Berdasarkan kerangka konseptual yang telah disampaikan pada bagian sebelumnya, dapat ditarik suatu hipotesis penelitian yang akan diuji kebenarannya dengan menggunakan fakta-fakta yang diperoleh dari penelitian terdahulu. Hipotesis ini masih dugaan sementara yang masih memerlukanpengujian kebenarannya lebih lanjut. Esensi dari pengujian hipotesis dalam penelitian ini untuk menguji apakah hipotesis tersebut dapat diterima atau tidak, jika dihubungkan dengan fenomena yang kompleks diangkat dalam penelitian ini. Hipotesis - hipotesis dalam penelitian ini adalah sebagai berikut :

H1 : Brand Association dan Brand Awereness berpengaruh langsung terhadap Brand Trust pada start up OVO

$\mathrm{H} 2$ : Brand Association dan Brand Awereness berpengaruh langsung terhadap Brand Loyalty pada start up OVO

H3 : Brand Trust berpengaruh langsung terhadap Brand Loyalty pada start up OVO

H4 : Brand Association dan Brand Awereness berpengaruh tidak langsung terhadap Brand Loyalty Melalui Brand Trust pada start up OVO

\section{METODE PENELITIAN}

Jenis penelitian yang digunakan dalam penelitian ini yaitu Penelitian explanatory reseacrh. Waktu penelitian direncanakan akan dilaksanakan mulai Bulan Oktober 2018 sampai dengan Bulan Desember 2018. Lokasi penelitian dilakukan pada mahasiswa Universitas Islam Malang. Populasi dalam penelitian ini adalah jumlah keseluruhan mahasiswa Universitas Islam Malang. Adapun jumlah Mahasiswa Universitas Islam Malang seluruhnya adalah 10.000 Mahasiswa

Pengambilan sampel yang digunakan non random sampling, yakni purposive sampling. Menggunakan purposive sampling karna responden harus memiliki syarat tertentu untuk bisa dijadikan sampel. Purposive sampling adalah teknik penentuan sampel dengan pertimbangan tertentu Sugiyono (2008:122).

Jadi dalam penelitian ini syarat untuk bisa dijadikan sampel yaitu:

a. Pengguna OVO

b. Berjenis Kelamin laki-laki dan wanita

c. Mengerti start up OVO

Alasan pemilihan teknik tersebut karna sampel tak bisa dibedakan secara langsung apakah responden pernah menggunakan OVO belum. Sehingga pengambilan sampel tak bisa dilakukan secara acak. Penelitian ini menggunakan 120 sampel yang berarti sudah memenuhi kriteria yaitu minimal 60 dan maksimal 120 . Teknik pengambilan sampel dengan cara purposive sampling dengan karakteristik responden dalam penelitian ini yaitu mahasiswa Universitas Islam Malang yang menggunakan aplikasi start up fintech OVO di smartphone.

Berdasarkan perumusan masalah dan kerangka pemikiran, maka penelitian ini menggunakan 3 dimensi konseptual pelayanan yang terdiri dari: Brand association, brand awareness, brand trust serta variabel brand loyalty 
Untuk menjawab tujuan pengaruh brand association dan brand awareness terhadap brand loyalty melalui brand trust pada start up fintech ovo dengan menggunakan analisis Structural Equation Modeling (SEM). Metode ini dipilih karena SEM dapat menjelaskan hubungan antar variable teramati (observed variables) dengan varibel-variabel laten melalui indikator indikatornya.Tidak seperti regresi pada umumnya, hanya bisa menjelaskanhubungan kausal antar variabel-variabel teramati saja. untuk menguji model ini, karena di dalamnya terdapat variabel-variabel laten (LV) dan variable teramati atau variabel obeservasi yang mempunyai pengukuran model variabel laten dipenden dengan second order confirmatory factors analysis (2ndCFA) menggunakan aplikasi warpPls 5.0.

Spesifikasi model pada tahap pertama berkaitan dengan pembentukan hubungan antar variabel di dalam SEM. Karena SEM bukan merupakan metode untuk membangun sebuah teori maka spesifikasi model ini harus didasarkan pada teori yang ada. Beranjak dari landasan teori dan konsep yang berkait dengan permasalahan pada peneliti ini spesifikasi model dapat dijelaskan dan disajikan dalam diagram berikut :

1. Variabel laten endogen.

Y1 = Brand Trust

$\mathrm{Y} 2=$ Brand Loyalty

2. Variabel laten eksogen

$\mathrm{X} 1=$ Brand Association

$\mathrm{X} 2$ =Brand Awareness

Dalam model formatif, setiap indikator empirik merepresentasikan indikator yang dapat tidak homogen dan tidak unidimensional. Semua indikator membentuk kombinasi persamaan regresi dalam menjelaskan konstrak latennya. Semua indikator tidak harus memiliki varians bersama (kovarians) sehingga mengeliminasi satu indikator tidak mengubah peranan indikator lainnya

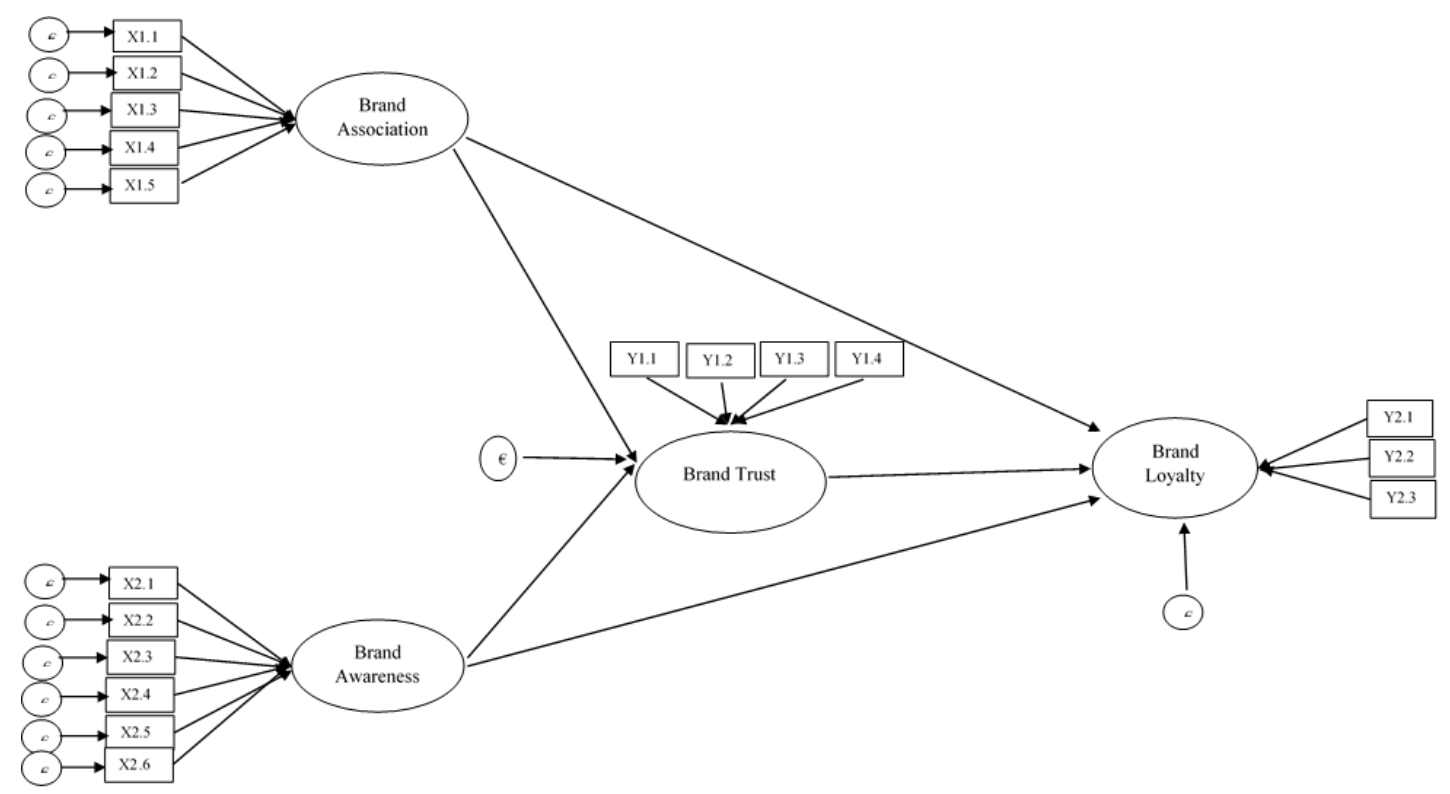

Gambar 3.5

Full Model vareabel formatif 


\section{HASIL ANALISIS DATA}

Berdasarkan hasil penyebaran kuisoner, gambaran umum responden berdasarkan jenis kelamin seperti disajikan pada tabel berikut:

Tabel. 4.1

Karakteristik Responden Bedasarkan Jenis Kelamin

\begin{tabular}{|l|l|l|l|}
\hline No & Jenis Kelamin & Jumlah & Prosentase (\%) \\
\hline 1 & Laki - Laki & 43 & 35,83 \\
\hline 2 & Perempuan & 77 & 64,17 \\
\hline Total & 120 & 100 \\
\hline
\end{tabular}

Berdasarkan table 4.1 dapat diketahui bahwa jumlah responden laki laki sebanyak 43 orang responden atau 35,83 \% sedangkan responden perempuan sebanyak 77 orang responden atau $64,17 \%$, hal ini berarti bahwa mayoritas responden adalah perempuan.

Berdasarkan hasil penyebaran kuisoner, gambaran umum responden berdasarkan jenis umur seperti disajikan pada tabel berikut:

Tabel. 4.2

Karakteristik Responden Bedasarkan Umur

\begin{tabular}{|l|l|l|l|}
\hline No & Umur Responden & Jumlah & Prosentase (\%) \\
\hline 1. & $21-30$ Tahun & 103 & 85,83 \\
\hline 2. & $\geq 31-40$ Tahun & 17 & 14,17 \\
\hline Total & 120 & 100 \\
\hline
\end{tabular}

Sumber: Data Primer diolah (Des. 2018)

Berdasarkan table 4.2. dapat diketahui bahwa 10 orang atau 85,83 $\%$ berusia kisaran 21 - 30 tahun, 17 orang responden atau 14,17\% berusia kisaran $\geq 31-40$ tahun. Hal ini menunjukkan bahwa responden mahasiswa Universitas Islam Malang paling besar adalah usia muda antara 21 - 30 tahun. Sesuai dengan kajian pustaka dan tujuan penelitian maka dapat dikembangkan model struktur sebagai berikut:

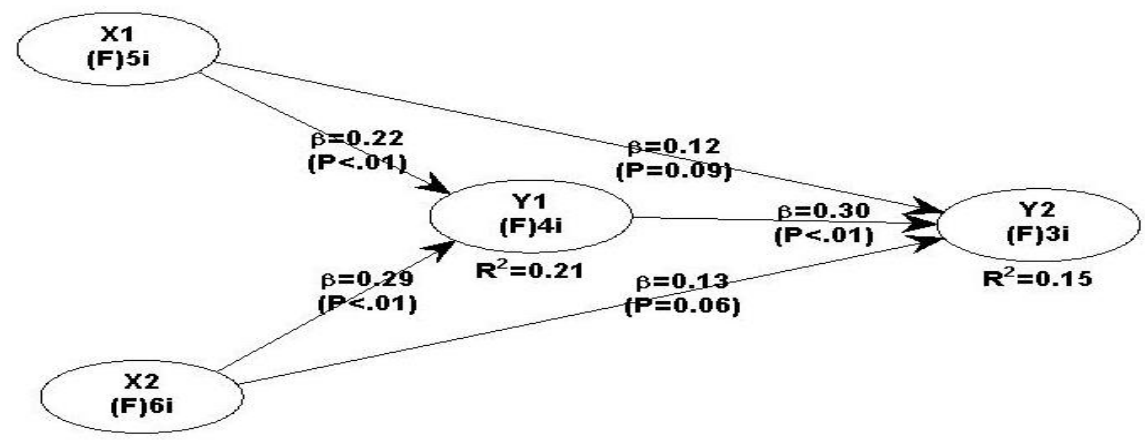

Gambar 4.2.

Full Model Struktur 
Dari gambar diatas menunjukkan bahwa terjadi pengaruh langsung yang signifikan antara Brand association (X1) terhadap Brand trust (Y1) yang ditunjukkan dengan koefisien 0,22 , begitu juga dengan brand awareness (X2) terhadap Brand trust (Y1) juga signifikan yang ditunjukkan dengan koefisien 0,29, Brand association (X1) tidak berpengaruh langsung terhadap brand loyalty (Y2) tidak signifikan ini ditunjukan dengan koefisien 0,12 , pengaruh brand awareness (X2) terhadap brand loyalty (Y2) tidak signifikan ini ditunjukkan dengan hasil 0,13, sedangkan Brand trust (Y1) terhadap peningkatan brand loyalty (Y2) berpengaruh signifikan ini dengan hasil 0,30. Dari hasil gambar ful model struktur diatas indikator dikatakan signifikan jika nilainya $>0,22$

Tabel 4.10 .

Pengujian Goodness Of Fit Ful Model Struktural

\begin{tabular}{|c|c|c|c|c|}
\hline No & Godness Of Fit Indeks & Kriteria Fit & Hasil Model & Ket. \\
\hline 1 & $\begin{array}{l}\text { Average path coefficient } \\
\text { (APP) }\end{array}$ & $p<0.05$ & $0,213, p=0,001$ & Baik \\
\hline 2 & Average R-squared (ARS) & $\mathrm{p}<0.05$ & $0,181, p<0,001$ & Baik \\
\hline 3 & $\begin{array}{l}\text { Average adjusted R-squared } \\
\text { (AARS) }\end{array}$ & $p<0.05$ & $0,163, p<0,001$ & Baik \\
\hline 4 & Average block VIF(AVIF) & $\begin{array}{l}\text { Acceptable if }<=5 \text {, } \\
\text { ideally }<=3.3\end{array}$ & $\begin{array}{l}1,286, \quad \text { acceptable } \\
\text { if }<=5, \text { ideally }<=3,3\end{array}$ & Baik \\
\hline 5 & $\begin{array}{l}\text { Average Full collinearity VIF } \\
\text { (AFVIF) }\end{array}$ & $\begin{array}{l}\text { Acceptable if }<=5 \text {, } \\
\text { ideally }<=3.3\end{array}$ & $\begin{array}{l}1,217, \quad \text { acceptable } \\
\text { if }<=5, \text { ideally }<=3,3\end{array}$ & Baik \\
\hline 6 & Tenenhaus Gof (GOF) & $\begin{array}{l}\text { Small }>=0.1, \text { medium } \\
>=0.25, \text { large }>=0.36\end{array}$ & $\begin{array}{l}0,288, \text { Small }>=0.1, \\
\text { medium }>=0.25, \text { large } \\
>=0.36\end{array}$ & Baik \\
\hline 7 & $\begin{array}{l}\text { Sympson's paradox ratio } \\
\text { (RSCR) }\end{array}$ & $\begin{array}{l}\text { Acceptable if }>=0.7 \\
\text { ideally }=1\end{array}$ & $\begin{array}{l}1000, \text { acceptable if } \\
>=0.7, \\
\text { ideally }=1\end{array}$ & Baik \\
\hline 8 & $\begin{array}{l}\text { R-squared contribution ratio } \\
\text { (RSCR) }\end{array}$ & $\begin{array}{l}\text { Acceptable if }>=0.9 \text {, } \\
\text { ideally }=1\end{array}$ & $\begin{array}{l}1,000, \text { acceptable if } \\
>=0.9, \\
\text { ideally }=1\end{array}$ & Baik \\
\hline 9 & $\begin{array}{l}\text { Statistical suppression ratio } \\
\text { (SSR) }\end{array}$ & Acceptable if $>=0.7$ & $\begin{array}{l}1,000, \text { acceptable if } \\
>=0.7\end{array}$ & Baik \\
\hline 10 & $\begin{array}{l}\text { Nonlinear bivariate causality } \\
\text { direction ratio (NLBCDR) }\end{array}$ & Acceptable if $>=0.7$ & $\begin{array}{l}1,000, \text { acceptable if } \\
>=0.7\end{array}$ & Baik \\
\hline
\end{tabular}

Sumber Data Primer diolah ( Des 2018)

Berdasarkan table diatas dapat dijelaskan bahwa Average path coefficient (APP) baik dilihat dari hasil analisis 0,001 dimana jika indeks dibawah 0,05, Average R-squared (ARS) baik dilihat dari hasil analisis 0,001 dimana jika indeks dibawah 0,05,Average adjusted R-squared (AARS) baik dilihat dari hasil analisis 0,001 dimana jika indeks dibawah 0,05 , Average block VIF(AVIF) baik dari hasil analisis acceptable if $<=5$, ideally $<=3,3$ dimana jika indeks sama dengan acceptable if $<=5$, ideally $<=3,3$, Average Full collinearity VIF (AFVIF) baik dimana hasil analisis acceptable if $<=5$, ideally $<=3,3$ dimana jika indeks sama dengan acceptable if $<=5$, ideally $<=3,3$, Tenenhaus Gof (GOF) baik dengan hasil small $>=0,1$, medium $>=0.25$, large $>=0.36$ jika indeks sama dengansmall $>=0,1$, medium $>=0.25$, large $>=0.36$, Sympson's paradox ratio (RSCR) baik dengan hasil acceptable if $>=0,7$ idealy $=1$ dimana jika indeks 
sama dengan acceptable if $>=0,7$ idealy $=1, \mathrm{R}$-squared contribution ratio (RSCR) baik ini dengan hasilacceptable if $>=0,9$ idealy $=1$ dimana jika indeks sama dengan acceptable if $>=0,9$ idealy $=1$, Statistical suppression ratio (SSR) baik dengan hasil acceptable if $>=0,7$ dimana jika indeks sama denganacceptable if $>=0,7$, Nonlinear bivariate causality direction ratio (NLBCDR) baik dengan hasil acceptable if $>=0,7$ dimana jika indeks sama denganacceptable if $>=0,7$.

Tabel 4.18.

Linier And Nonlinier (“Warped") Relationsship Among Latent Variables

\begin{tabular}{|l|l|l|l|l|}
\hline & $\mathrm{X} 1$ & $\mathrm{X} 2$ & $\mathrm{X} 3$ & $\mathrm{Y}$ \\
\hline $\mathrm{X} 1$ & & & & \\
\hline $\mathrm{X} 2$ & & & & \\
\hline $\mathrm{X} 3$ & Warped & Warped & & \\
\hline $\mathrm{Y}$ & Warped & Warped & Warped & \\
\hline
\end{tabular}

Sumber: data primer diolah (Des 2018)

Dari table diatas dapat dilihat bahwa hubungan antar vareabel menunjukkan hubungan yang nonlinier (warped).

\section{PEMBAHASAN}

\section{Pengaruh Langsung Brand Association dan Brand Awareness terhadap Brand Trust}

Uji pengaruh brand association (X1) terhadap Brand Trust (Y1) menunjukkan nilai koefisien 0,22 dengan $\mathrm{P}<0,01$, hal ini berarti brand association berpengaruh langsung signifikan terhadap brand trust. Sedangkan untuk uji pengaruh brand awarennes (X2) terhadap Brand Trust (Y1) menunjukkan nilai koefisien 0,29 dengan $P<0,0$, hal ini berarti brand awareness berpengaruh langsung signifikan terhadap brand trust. Maka dapat dinyatakan bahwa brand association dan brand awareness berpegaruh langsung terhadap brand trust.

Hasil penelitian ini konsisten dengan pendapat Lau dan Lee dalam jurnal yang ditulis oleh Tjahyadi (2006:71) yang menyatakan bahwa kepercayaan konsumen pada merek (brand trust) didefinisikan sebagai keinginan pelanggan untuk bersandar pada sebuah merek dengan risikorisiko yang dihadapi karena ekspektasi terhadap merek itu akan menyebabkan hasil yang positif. Dengan demikian merek yang dirasa aman membuat konsumen merasa nyaman dan terhidar dari resiko yang ada dalam mengkonsumsi produk tersebut.

\section{Pengaruh Langsung Brand Association dan Brand Awareness terhadap Brand Loyalty}

Uji pengaruh brand association (X1) terhadap Brand Loyalty (Y2) menunjukkan nilai koefisien 0,12 dengan $P=0,09$, hal ini berarti brand association tidak signifikan terhadap brand loyalty. Sedangkan untuk uji pengaruh brand awareness (X2) terhadap Brand Loyalty (Y2) menunjukkan nilai koefisien 0,16 dengan $P=0,06$, hal ini berarti brand awareness tidak signifikan terhadap brand loyalty. Maka dapat dinyatakan bahwa brand association dan brand awareness tidak berpengaruh langsung terhadap brand Loyalty.

Pengaruh Langsung Brand Trust Terhadap Brand Loyalty 
Uji pengaruh brand Trust (Y1) terhadap Brand Loyalty (Y2) menunjukkan nilai koefisien 0,30 dengan $P<0,01$, dari hasil uji tersebut berarti brand Trust berpengaruh signifikan terhadap brand loyalty. Maka dapat dinyatakan brand trust berpengaruh langsung terhadap brand loyalty.

Hasil penelitian di atas juga sesuai dengan hasil penelitian terdahulu yang telah dibuat oleh Danny Alexander Bastian (2014) Dengan Judul Analisa Pengaruh Citra Merek (Brand Image) dan Kepercayaan Merek (Brand Trust) Terhadap Loyalitas Merek (Brand Loyalty) ADES PT. Ades Alfindo Putra Setia. Variabel brand trust berpengaruh terhadap brand loyalty. Hal ini menunjukkan upaya yang ada dalam membangun kepercayaan konsumen melalui pemenuhan kebutuhan keinginan konsumen akan air minum kemasan.

Hasil penelitian ini juga didukung oleh penel itian Dr. Wati Susilawati dan Wufron (2017) Dengan Judul pengaruh brand image terhadap brand trsut serta implikasinya terhadap brand loyality (produk dodol PT. Herlinah cipta pratama). Hasil penelitian menjelaskan bahwa brand image berpengaruh positif dan signifikan terhadap brand trust, brand image berpengaruh positif dan signifikan terhadap brand loyallity, brand trust berpengaruh positif dan signifikan terhadap brand loyallity, serta didapat kesimpulan bahwa brand image dapat berpengaruh signifikan terhadap brand loyallity melalui brand trust.

Selain itu hasil ini mendukung teori lau dan lee (1999) yang menyatakan dalam membangun dan mengembangkan brand trust perusahaan harus memahami tiga karakteristik penting sebagai determinan kepercayaan pelanggan, yang pada akhirnya akan mengarah pada loyalitas pelanggan.

\section{Pengaruh Tidak langsung brand association dan brand awareness terhadap brand loyalty melalui brand trust}

Pengaruh tidak langsung antara variabel brand association terhadap brand loyalty melalui variabel brand trust diperoleh dari hasil pengaruh langsung antara variabel brand association terhadap brand trust sebesar 0,22 dan pengaruh langsung antara variabel brand trust terhadap variabel brand loyalty sehingga pengaruh tidak langsung sebesar 0,30.

Pengaruh tidak langsung antara variabel brand Awareness terhadap brand loyalty melalui variabel brand trust diperoleh dari hasil pengaruh langsung antara variabel brand awareness terhadap brand trust sebesar 0,29 dan pengaruh langsung antara variabel brand trust terhadap variabel brand loyalty sehingga pengaruh tidak langsung sebesar 0,30 . Hal ini dapat diartikan bahwa ada pengaruh tidak langsung variabel brand association dan brand awareness terhadap brand loyalty melalui brand trust, serta semakin tinggi brand trust maka brand loyalty akan semakin meningkat.

\section{SIMPULAN DAN SARAN}

Brand association berpengaruh langsung signifikan terhadap brand trust dan brand awareness berpengaruh langsung signifikan terhadap brand trust. Maka dapat dinyatakan bahwa brand association dan brand awareness berpegaruh langsung terhadap brand trust pada start up fintech OVO. Brand association tidak signifikan terhadap brand loyalty dan brand 
awareness tidak signifikan terhadap brand loyalty. Maka dapat dinyatakan bahwa brand association dan brand awareness tidak berpengaruh langsung terhadap brand Loyalty. Brand Trust berpengaruh langsung signifikan terhadap brand loyalty.

Pengaruh tidak langsung antara variabel brand Awareness terhadap brand loyalty melalui variabel brand trust diperoleh dari hasil pengaruh langsung antara variabel brand awareness terhadap brand trust dan pengaruh langsung antara variabel brand trust terhadap variabel brand loyalty sehingga pengaruh tidak langsung. Hal ini dapat diartikan bahwa ada pengaruh tidak langsung variabel brand association dan brand awareness terhadap brand loyalty melalui brand trust, serta semakin tinggi brand trust maka brand loyalty akan semakin meningkat.

\section{DAFTAR PUSTAKA}

A Aaker, David A. (2008) Manajemen Ekuitas merek. Jakarta: Mitra Utama Amstrong, M. (2002). Performance Management. Kogan Page Ltd. New York. A. Shimp

Arikunto, Suharsimi. (2005). Prosedur Penelitian Suatu Pendekatan Praktek. Edisi Keempat. Jakarta: Penerbit Rineka Cipta

Alma, Buchari. (2004). Manajemen Pemasaran dan Pemasaran Jasa. Cetakan Keenam. Alfabeta. Bandung.

Cooper, Donald R. 2000. Metode Penelitian Bisnis. Edisi ke-5, Jilid 2. Erlangga : Jakarta.

Indriantoro, Nur dan Bambang Supomo. 2002. Metodologi Penelitian Bisnis. Edisi 1.Penerbit BPFE. Yogyakarta.

J.Setiadi 2010. Perilaku Konsumen, KENCANA prenada media group :Jakarta

Kotler, Philip. (2000). Manajemen Pemasaran. Jilid 2. Jakarta. Bumi Aksara.

Kotler, Philip. (2000). Marketing Management. The Millenium Edition. Upper Saddle River: Prentice Hall International, Inc

Kotler, Philip dan K. L. Keller. (2007). Manajemen Pemasaran, Ed.12. jilid1. Jakarta: Indeks

Kotler, Philip. (2009). Manajemen Pemasaran (Terjemahan) Jilid 9. Jakarta : PT. Prehallindo.

Kotler, Philip. (2010). Manajemen Pemasaran. Edisi ke-13, Jilid 1. Terjemahan: Bob Sabran. Erlangga : Jakarta.

Oentoro, Deliyanti, SE., MM. (2010). Manajemen Pemasaran Modern. Cetakan 12.Yogyakarta : LaksBang Pressindo.

Radiosunu. (2001). Manajemen Pemasaran; Suatu Pendekatan Analisis. Edisi Kedua.Universitas Gajah Mada. Yogyakarta.

Sekaran, Uma. 2006. Research Methods For Business, Metodologi

Penelitian Bisnis 2. Jakarta : Salemba Empat

Sugiyono. 2008. Metode Penelitian Bisnis. Bandung: Alfabeta

Stanton, William J. (2001). Prinsip Pemasaran. Edisi ketujuh. Jakarta : Erlangga. 
Sugiyono, (2010). Metode Penelitian Kuantitatif Kualitatif dan R\&D. Bandung: Alfabeta

Susanto, A. B. (2007). Manajemen Pemasaran. Jakarta : PT. Prenhalindo.

Swastha, Basu dan Irawan. (2000). Manajemen Pemasaran Modern. Liberty. Jakarta.

Tjiptono, Fandy. (2002). Strategi Pemasaran. Yogyakarta : Penerbit Andi.

Terence. (2003). Periklanan Promosi. Jakarta : Erlangga. Assauri, Sofyan dan Irawan. 2000. Manajemen Pemasaran Modern. Liberty. Yogyakarta.

Tjiptono, F. 2005. Brand Management and Strategy. Yogyakarta : Andi Offset.

https://www.ovo.id/faq

Andri Donnal Putera "Melihat Strategi "Open Platform" Ala OVO", https://ekonomi.kompas.com/read/2018/05/28/090900226/melihatstrategi-open-platform-ala-ovo. Diakses 21 oktober 2018. 